\title{
Determination of Anti-virus Drug, Ganciclovir, in Human Serum by HPLC with Precolumn Fluorescence Derivatization Using Phenylglyoxal
}

\author{
Masahiko Tsuchie,* Shuuji Hara, *† Masahiko Kimura,* Megumi FujII,* \\ Nobufumi ONO,* and Masaaki KAI** \\ *Faculty of Pharmaceutical Sciences, Fukuoka University, Nanakuma, Jonan, Fukuoka 814-0180, Japan \\ **School of Pharmaceutical Sciences, Nagasaki University, Bunkyo-Machi, Nagasaki 852-8521, Japan
}

\begin{abstract}
A selective and highly sensitive liquid chromatographic method for the determination of ganciclovir (anti-virus drug) in human serum was described. After ganciclovir and acyclovir (internal standard; IS) were extracted with solid-phase extraction cartridge from serum, they were converted into fluorescent derivatives by reaction with phenylglyoxal in a phosphate buffer ( $\mathrm{pH} 5.8)$ at $20^{\circ} \mathrm{C}$ for $30 \mathrm{~min}$. The derivatives were separated by reversed-phase column with a mixture of acetonitrile-1 mM phosphate buffer $(\mathrm{pH} 6.2)(18: 82, \mathrm{v} / \mathrm{v})$, and were then detected spectrofluorometrically at $512 \mathrm{~nm}$ with excitation at $365 \mathrm{~nm}$. Extraction recoveries were $87.0-91.6 \%$ for ganciclovir and $86.8-92.3 \%$ for IS. The detection limit for ganciclovir spiked to serum was $5 \mathrm{ng} \mathrm{ml}^{-1}$ serum (306 fmol on column) at a signal-to-noise ratio of three. The accuracy and precision of this method were $7.6 \%$ and $5.0 \%$ even at low concentration $\left(20 \mathrm{ng} \mathrm{ml}^{-1}\right)$. The within- and between-day variations are lower than $7.6 \%$ and $8.1 \%$, respectively.
\end{abstract}

(Received March 23, 2001; Accepted May 9, 2001)

Ganciclovir, 9-(1,3-dihydroxy-2-propoxymethyl)guanine (Fig. $1 \mathrm{~A})$, is a nucleoside analogue that has shown activity against viruses of the herpes group, including cytomegalovirus. ${ }^{1}$ Ganciclovir is an effective therapy for cytomegalovirus infection in immunocompromised patients such as patients with acquired immunodeficiency syndrome or patients in immunosuppressive therapy following organ transplantation. ${ }^{2,3}$

Several methods used up to now to determine the ganciclovir level have been based on either chromatographic or immunochemical techniques. Although both a radioimmunoassay or an enzyme-linked immunosorbent assay have been very sensitive, these methods require a number of steps for sample clean-up. Some high-performance liquid chromatographic (HPLC) methods with $\mathrm{UV}^{4-11}$ and native fluorometric ${ }^{12,13}$ detections have also been developed to determine the ganciclovir level in human serum. However, these methods show low selectivity and/or poor sensitivity, and also require tedious sample clean-up procedures. Recently, an HPLC-mass spectrometric method has been reported. ${ }^{14}$ This method is extremely specific, but requires sophisticated instrumentation.

We reported previously that phenylglyoxal (PGO) reacts selectively with guanine-containing compounds to produce fluorescent derivatives. ${ }^{15,16}$ This paper describes the optimum derivatization conditions for ganciclovir and acyclovir (IS), and an HPLC method with precolumn derivatization utilizing these reaction conditions for selective and sensitive determination of the drug in serum.

\footnotetext{
$\doteqdot$ To whom correspondence should be addressed.
}

\section{Experimental}

\section{Chemicals and solutions}

All chemicals were of analytical-reagent grade, unless otherwise noted. Distilled water, purified with Milli-Q system (Japan Millipore Ltd., Tokyo, Japan), was used for all aqueous solutions. Ganciclovir and IS were purchased from Sigma (St. Louis, MO, USA). A PGO monohydrate was from Aldrich (Milwaukee, WI, USA).

PGO solution (130 mM) was prepared in dimethyl sulfoxide. Both ganciclovir and IS solutions (400 $\mu \mathrm{g} / \mathrm{ml}$ each) were

A

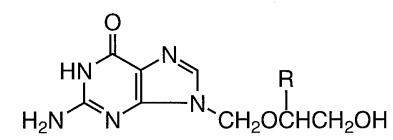

$\mathrm{R}=\mathrm{CH}_{2} \mathrm{OH}$ : ganciclovi $\mathrm{R}=\mathrm{H}$ : acyclovir (IS)

$B$

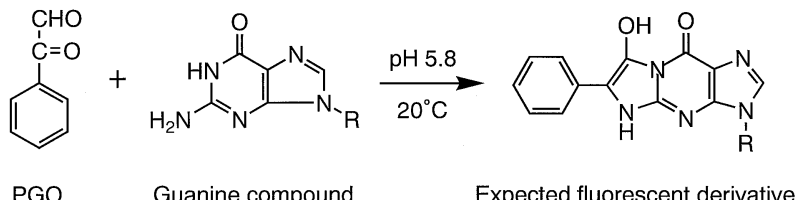

Fig. 1 (A) Chemical structures of ganciclovir and acyclovir (IS), and (B) scheme of the expected fluorescence reaction between PGO and their compounds. 


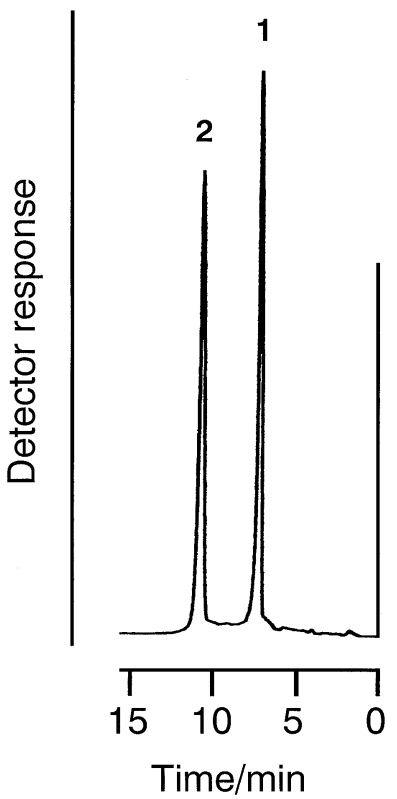

Fig. 2 Chromatogram of PGO derivatives of ganciclovir and IS. A portion $(100 \mu \mathrm{l})$ of a standard mixture of the compounds $\left(1 \mu \mathrm{g} \mathrm{ml}^{-1}\right.$ each) was treated according to the fluorescence derivatization procedure. Peaks: 1, ganciclovir; 2, IS.

prepared in water and stored in a refrigerator at $4^{\circ} \mathrm{C}$. Before undergoing analysis, they were then further diluted to appropriate concentrations with water.

Sera were obtained from healthy volunteers in our laboratories.

\section{HPLC apparatus and conditions}

A Shimadzu LC-10AT high-performance liquid chromatograph equipped with a sample injector (10- $\mu$ l loop) and a Shimadzu RF-10AXL fluorescence detector fitted with a $12-\mu \mathrm{l}$ flow-cell were used. It was operated at an excitation wavelength of $365 \mathrm{~nm}$ and an emission wavelength of $512 \mathrm{~nm}$. The separations were performed on a Develosil RPAQUEOUS reversed-phase column $(150 \times 4.6 \mathrm{~mm}$ i.d., $5 \mu \mathrm{m}$; Nomura Chemical Co., Ltd, Aichi, Japan), by isocratic elution with a mixture of acetonitrile-1 mM phosphate buffer ( $\mathrm{pH}$ 6.2) (18:82, $\mathrm{v} / \mathrm{v}$ ) at a flow-rate of $1.0 \mathrm{ml} / \mathrm{min}$. The column temperature was ambient $\left(20-25^{\circ} \mathrm{C}\right)$. The uncorrected fluorescence excitation and emission spectra of the eluates were measured with a Hitachi 650-60 fluorescence spectrophotometer (Tokyo, Japan) fitted with a $20-\mu$ flow-cell; the spectral bandwidths were $5 \mathrm{~nm}$ in both the excitation and emission monochromators.

\section{Fluorescence derivatization}

A $100-\mu 1$ aliquot of a test solution was spiked in a test tube, to which were added $50 \mu \mathrm{l}$ each of the PGO $(130 \mathrm{mM})$ and $30 \mathrm{mM}$ phosphate buffer ( $\mathrm{pH}$ 5.8). After stirring, the mixture was allowed to stand at $20^{\circ} \mathrm{C}$ for $30 \mathrm{~min}$. A $10-\mu \mathrm{l}$ portion of the final reaction mixture was used for HPLC. To prepare the reagent blank, a $100-\mu 1$ volume of water in place of test solution was carried out through the procedure.

\section{Extraction from serum}

A $250-\mu \mathrm{l}$ aliquot of human serum was added with $10 \mu \mathrm{l}$ of the IS solution $\left(15 \mu \mathrm{g} \mathrm{ml}^{-1}\right)$. The mixture was loaded onto the solid-phase extraction cartridge (Oasis $\mathrm{HLB}^{\circledR}, 30 \mathrm{mg}, 1 \mathrm{ml}$, Waters) which was preconditioned with $1 \mathrm{ml}$ of methanol and 1

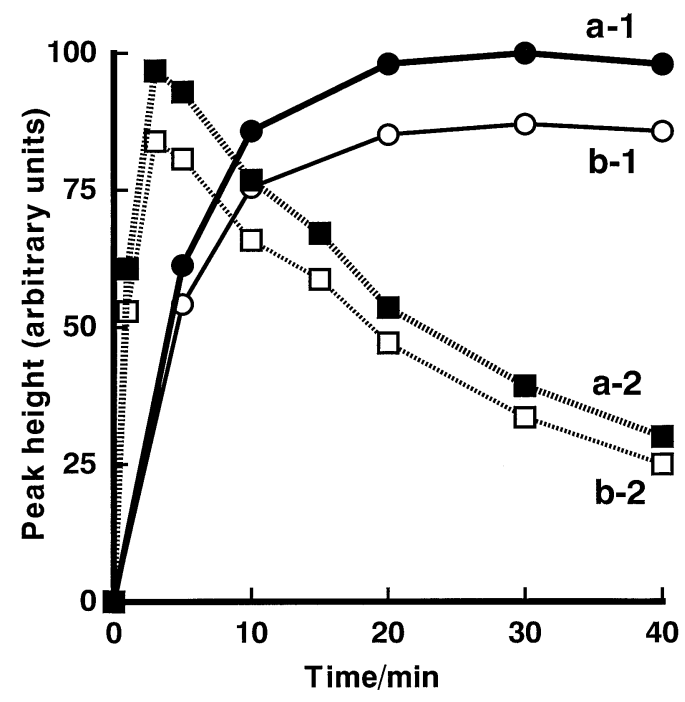

Fig. 3 Effect of reaction temperature and time on the peak height of ganciclovir (a) and IS (b). Portions (100 $\mu \mathrm{l})$ of ganciclovir and IS solution $\left(1 \mu \mathrm{g} \mathrm{ml}{ }^{-1}\right.$ each) were treated according to the derivatization procedure. Temperature: $1,20^{\circ} \mathrm{C} ; 2,37^{\circ} \mathrm{C}$

$\mathrm{ml}$ of water, and washed with $200 \mu \mathrm{l}$ of water. Ganciclovir and IS were eluted from the sorbent with $750 \mu \mathrm{l}$ of $10 \%$ methanol. The eluate was evaporated to dryness under compressed air at $55^{\circ} \mathrm{C}$. The residue was then dissolved in $100 \mu \mathrm{l}$ of water, and the mixture was treated according to the above derivatization procedure.

The calibration graph was prepared as in the above procedure, except that $10 \mu \mathrm{l}$ of the IS solution was replaced with IS solutions each containing $5 \mathrm{ng}-2.0 \mathrm{mg}$ of ganciclovir. The net peak height ratios of the drug and IS were plotted against the concentrations of the spiked drug.

\section{Results and Discussion}

\section{HPLC conditions and derivatization conditions}

The best separation of the PGO derivatives of ganciclovir and IS was achieved on a Develosil RPAQUEOUS reversed-phase column with acetonitrile-1 $\mathrm{mM}$ phosphate buffer $(\mathrm{pH}$ 6.2) $(18: 82, v / v)$ as an eluent. Figure 2 shows a typical chromatogram obtained with a standard mixture of ganciclovir and IS. Ganciclovir and IS gave single peaks and had retention times of 7.4 and $10.7 \mathrm{~min}$, respectively (Fig. 2). Both of the eluates from their peaks showed almost identical fluorescence excitation (maxima, $365 \mathrm{~nm}$ ) and emission (maxima, $512 \mathrm{~nm}$ ) spectra.

The derivatization reaction of ganciclovir and IS with PGO apparently occurred even at room temperature (Fig. 3). However, at $37^{\circ} \mathrm{C}$, these derivatives were drastically decomposed over a longer time $(>3 \mathrm{~min})$. At $20^{\circ} \mathrm{C}$, the peak heights for both the compounds were almost maximal for 20 min. Thus this procedure includes allowing to stand for $30 \mathrm{~min}$ at $20^{\circ} \mathrm{C}$. The $\mathrm{PGO}$ derivatives in the final mixture were stable and gave a constant peak heights for at least $24 \mathrm{~h}$ in daylight at below $4^{\circ} \mathrm{C}$.

The $\mathrm{pH}$ of the reaction mixture greatly affected the fluorescence production. Maximum and stable peak heights were attained at phosphate buffer $\mathrm{pH} 5.8$. The concentration of the phosphate buffer ( $\mathrm{pH}$ 5.8) also influenced the fluorescence derivatization. Most peak heights were greatest at a 
Table 1 Extraction recoveries of ganciclovir and IS from the spiked sera

\begin{tabular}{ccc}
\hline \multirow{2}{*}{ Concentration } & \multicolumn{2}{c}{ Recovery, $\%$ (mean $\pm \mathrm{SD}, n=7$ each) } \\
\cline { 2 - 3 } & Ganciclovir & IS \\
\hline $8.0 \mu \mathrm{g} / \mathrm{ml}$ & $87.0 \pm 2.5$ & $86.8 \pm 2.0$ \\
$0.4 \mu \mathrm{g} / \mathrm{ml}$ & $91.6 \pm 1.7$ & $92.3 \pm 1.8$ \\
$20 \mathrm{ng} / \mathrm{ml}$ & $89.2 \pm 3.8$ & $90.0 \pm 3.4$ \\
\hline
\end{tabular}

(A)

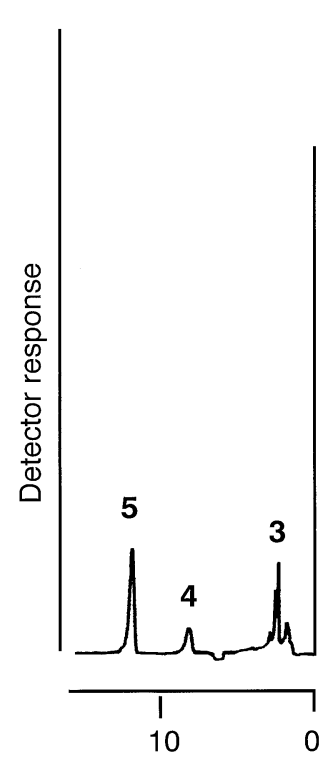

Time/min
(B)

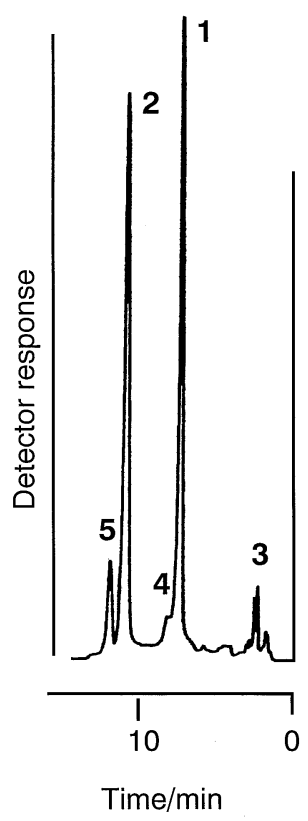

Fig. 4 Chromatograms obtained with (A) drug-free serum and (B) serum spiked with ganciclovir and IS (600 ng ml-1 each). Peaks: 1 2 as in Fig. 2; others, endogenous substances.

concentration of $7.5 \mathrm{mM}$ in the reaction mixture.

\section{Quantitative analysis of ganciclovir in human serum}

Since ganciclovir is highly polar, the extraction of the drug from serum commonly requires multi-clean-up procedures, i.e. deproteinization, neutralization and liquid-liquid extraction. ${ }^{5}$ We found that ganciclovir and IS were effectively extracted from serum with a solid-phase extraction cartridge (Oasis $\left.\mathrm{HLB}^{\circledR}\right)$. The recoveries of ganciclovir and IS were studied (Table 1). The individual extraction efficiencies of ganciclovir and IS were excellent and almost the same in the concentration range of $20 \mathrm{ng}-8.0 \mu \mathrm{g} \mathrm{ml}^{-1}$.

Figure 4 shows typical chromatograms obtained with the drug-free serum (A) and with the same serum (B) spiked with ganciclovir and IS. Some unidentified peaks (peaks 3-5, Fig. 4B) were observed on the chromatogram from drug-free serum, though these peaks almost never disturbed the precise determination of ganciclovir level in serum. Peaks 1 and 2 in Fig. 4B were attributed on the basis of their retention times in comparison with the standard, and also co-chromatography of the standard and a spiked serum sample using $10-25 \%(\mathrm{v} / \mathrm{v})$ acetonitrile as mobile phase.

The chemical structures of the fluorescent products in the reaction of ganciclovir and IS with PGO are still unknown.
Table 2 Accuracy and precision of the HPLC method for determining ganciclovir concentrations in serum samples

\begin{tabular}{cccr}
\hline $\begin{array}{c}\text { Actual } \\
\text { concentration }\end{array}$ & $\begin{array}{c}\text { Found }(n=10) \\
\text { Mean } \pm \text { SD }\end{array}$ & $\begin{array}{c}\text { RSD, } \\
\%\end{array}$ & $\begin{array}{c}\text { Bias }^{\mathrm{a}}, \\
\%\end{array}$ \\
\hline $8.0 \mu \mathrm{g} / \mathrm{ml}$ & $7.922 \pm 0.430$ & 5.3 & -0.98 \\
$0.4 \mu \mathrm{g} / \mathrm{ml}$ & $0.410 \pm 0.013$ & 2.9 & 0.25 \\
$20 \mathrm{ng} / \mathrm{ml}$ & $21.0 \pm 1.00$ & 7.6 & 5.00 \\
\hline
\end{tabular}

a. Bias $=($ actual concentration - found $) /$ actual concentration $\times 100$.

Table 3 Within- and between-day precisions of the HPLC method for determining ganciclovir concentrations in serum samples

\begin{tabular}{crcccc}
\hline \multirow{2}{*}{$\begin{array}{c}\text { Actual } \\
\text { concentration }\end{array}$} & \multicolumn{2}{c}{ Within-day $(n=10)$} & & \multicolumn{2}{c}{ Between-day $(n=10)$} \\
\cline { 2 - 3 } \cline { 5 - 6 } & Mean \pm SD & RSD, \% & & Mean \pm SD & RSD, \% \\
\hline $8.0 \mu \mathrm{g} / \mathrm{ml}$ & $7.922 \pm 0.430$ & 5.3 & & $7.877 \pm 0.396$ & 5.2 \\
$0.4 \mu \mathrm{g} / \mathrm{ml}$ & $0.4100 \pm 0.013$ & 2.7 & & $0.396 \pm 0.021$ & 3.8 \\
$20 \mathrm{ng} / \mathrm{ml}$ & $21.0 \pm 1.011$ & 7.6 & & $21.4 \pm 1.601$ & 8.1 \\
\hline
\end{tabular}

Ohba et al. guessed that guanine and 7-methylguanine react with 3,4-dimethoxyphenylglyoxal to produce imidazopurine derivatives. ${ }^{17}$ This indicates the PGO derivatives of ganciclovir and IS might be corresponding imidazo[1,2- $a$ ]purine derivatives (Fig. 1B).

A linear relationship was observed between the ratios of the peak height of ganciclovir to that of IS and the amounts of ganciclovir added to serum over the range of $20 \mathrm{ng}-8.0 \mu \mathrm{g} \mathrm{ml}^{-1}$ serum (The median in vitro inhibitory concentration of most cytomegalovirus isolates is $0.5-1.0 \mathrm{mg} \mathrm{ml}^{-1}$ ). The slope of the curve did not change with the serum used. The linearregression equation [the linear correlation coefficients $(n=7)$ in parentheses] of the curve for ganciclovir was $y=0.0011 x$ $0.0161(r=0.999)$, where $y$ and $x$ are the peak-height ratio and the concentration (ng $\mathrm{ml}^{-1}$ in the serum) of the drug, respectively. This result shows that the present IS method allows one to determine the level of ganciclovir in serum over a wide range of concentrations.

The accuracy and precision of the method are shown in Table 2. Accuracy, estimated as the deviation of the observed mean concentration from the actual concentration, was less than 5\% for all the concentrations examined. The within- and betweenday precisions were established by repeated determination of ganciclovir in serum spiked with ganciclovir at low, medium and high concentrations. These results are shown in Table 3. These data indicate that the HPLC method is reliable both within the same day and on different days.

The detection limits (signal-to-noise ratio $=3$ ) for ganciclovir was $5 \mathrm{ng}(20 \mathrm{pmol}) \mathrm{ml}^{-1}$ (306 fmol on column). The sensitivity is approximately 10 times higher than those of the HPLC methods. ${ }^{4-13}$

The present fluorometric HPLC method using PGO only needs one-step extraction with solid-phase cartridge for the determination of serum ganciclovir. Moreover, it is very sensitive and selective for ganciclovir, and may therefore be useful in routine analysis for the therapeutic drug monitoring of ganciclovir. Furthermore, this method may also be useful for conducting pharmacokinetic studies of ganciclovir. 


\section{References}

1. A. K. Fried, M. E. Davies, C. Dewitt, H. C. Perry, R. Liou, J. Germerhausen, J. D. Karkas, W. T. Ashton, D. B. R. Johnson, and R. L. Tolman, Proc. Natl. Acad. Sci. U.S.A., 1983, 80, 4139.

2. D. Faulds and R. C. Heel, Drugs, 1990, 39, 597.

3. A. Markham and D. Faulds, Drugs, 1994, 48, 455.

4. M. Merodio, M. A. Campanero, T. Mirshahi, M. Mirshahi, and J. M. Irache, J. Chromatogr. A, 2000, 870, 159.

5. M. A. Campanero, B. Sadaba, E. Garcia-Quetglas, and J. R. Azanza, J. Chromatogr. B, 1998, 706, 311.

6. M. Cociglio, H. Peyriere, D. Hillaire-Buys, and R. Alric, J. Chromatogr. B, 1998, 705, 79.

7. C. M. McMullin, B. Kirk, J. Sunderland, L. O. White, D. S. Reeves, and A. P. MacGowan, J. Antimicrob. Chemother., 1996, 38, 739 .

8. T. Page, C. Sherwood, J. D. Connor, and T. Tarnowski, J. Chromatogr. B, 1996, 675, 342.
9. R. Boulieu, N. Bleyzac, and S. Ferry, J. Chromatogr., 1991, 571, 331.

10. M. A. Hedaya and R. J. Sawchuk, Pharm. Res., 1990, 11, 1113.

11. J. P. Sommadossi and R. Bevan, J. Chromatogr., 1987, 414, 429.

12. F. Chu, C. H. Kiang, M. L. Sung, B. Huang, R. L. Reeve, and T. Tarnowski, J. Pharm. Biomed. Anal., 1999, 21, 657.

13. M. Koel and P. Nebinger, J. Pharm. Biomed. Anal., 1994, $12,429$.

14. K. Xu, M. Lanuti, E. S. Lambright, S. D. Force, S. M. Albelda, and I. A. Blair, Biomed. Chromatogr., 2000, 14, 93.

15. M. Kai, Y. Ohkura, S. Yonekura, and M. Iwasaki, Anal. Chim. Acta, 1988, 207, 243.

16. S. Yonekura, M. Iwasaki, M. Kai, and Y. Ohkura, J. Chromatogr., 1993, 641, 235.

17. Y. Ohba, M. Kai, and K. Zaitsu, Anal. Chim. Acta, 1998 , $365,233$. 